\title{
De Novo Chiari I Malformation and Syringomyelia Arising from Enlarging Posterior Fossae Meningioma: Case Report and Discussion
}

\author{
Shiau J S, Collado JA*, Danielle Ruggiero D and \\ Skrypek AR \\ Patient Care Administrator, USA \\ *Corresponding author: J esus A Collado, Patient Care \\ Administrator, USA
}

Received: J une 14, 2021; Accepted: July 13, 2021;

Published: July 20, 2021

\begin{abstract}
The authors believe this is the first described case completely illustrating the de novo development of Chiari I Malformation and associated syringomyelia in a patient with posterior fossae meningioma. The case demonstrates and supports current theories regarding Chiari I malformations and the pathophysiology of syringomyelia.
\end{abstract}

Keywords: Chiari I malformation; Pathophysiology; Meningiomas

\section{Introduction}

Syringomyelia can be associated with pathology in the craniocervical junction; however, the scenario of a Chiari I Malformation and syringomyelia arising from a posterior fossae meningioma is infrequent. We describe discuss a case of an enlarging infratentorial meningioma with radiographic progression showing de novo development of a Chiari I Malformation and syringomyelia.

\section{Case Presentation}

This patient is a 64-year-old woman with a history of breast carcinoma who was found to have two posterior fossae meningiomas during workup for a syncopal episode in 2007. A leS-sided cerebellar meningioma near the tentorium measured approximately $3 \mathrm{~cm}$ and, on the right, there was a smaller cerebellar meningioma measuring approximately $0.5 \mathrm{~cm}$. There was no associated edema or mass effect; there was no evidence of cerebellar tonsillar herniation or syrinx (Figure 1 and 2). She was asymptomatic and was administered serial scans.

Serial studies did show a progressive increase in the size of both meningiomas, but she remained asymptomatic until 2012. That year she noted occasional frontal headaches when she coughed; however, she denied any other symptoms. Her January 2012 MRI revealed a slight increase in the leS-sided meningioma measuring $3.6 \times 3.1 \times$ $3.8 \mathrm{~cm}$. There was some mild mass effect without any evidence of vasogenic edema. The right-sided meningioma measured $1.7 \times 1.4$ x $1.8 \mathrm{~cm}$, also slightly increased. Resection of the leS-sided lesion was recommended, but she declined. A year later, a February 2013 MRI showed minimal to no increase in size. She was relatively asymptomatic and opted for close follow up.

In February 2014, there were no major changes in her condition. She denied persistent headaches; however, she did again have a component of tussive headaches, which was apparent with coughing and sneezing. In addition, Valsalva maneuvers would also reproduce her symptoms, which was not apparent before. She experienced pressure on the back of the head and frontally. She denied neck pain, paresthesias, dysesthesias, or sensory changes in the extremities. She denied balance, fine motor, or gross motor changes or deficits. The
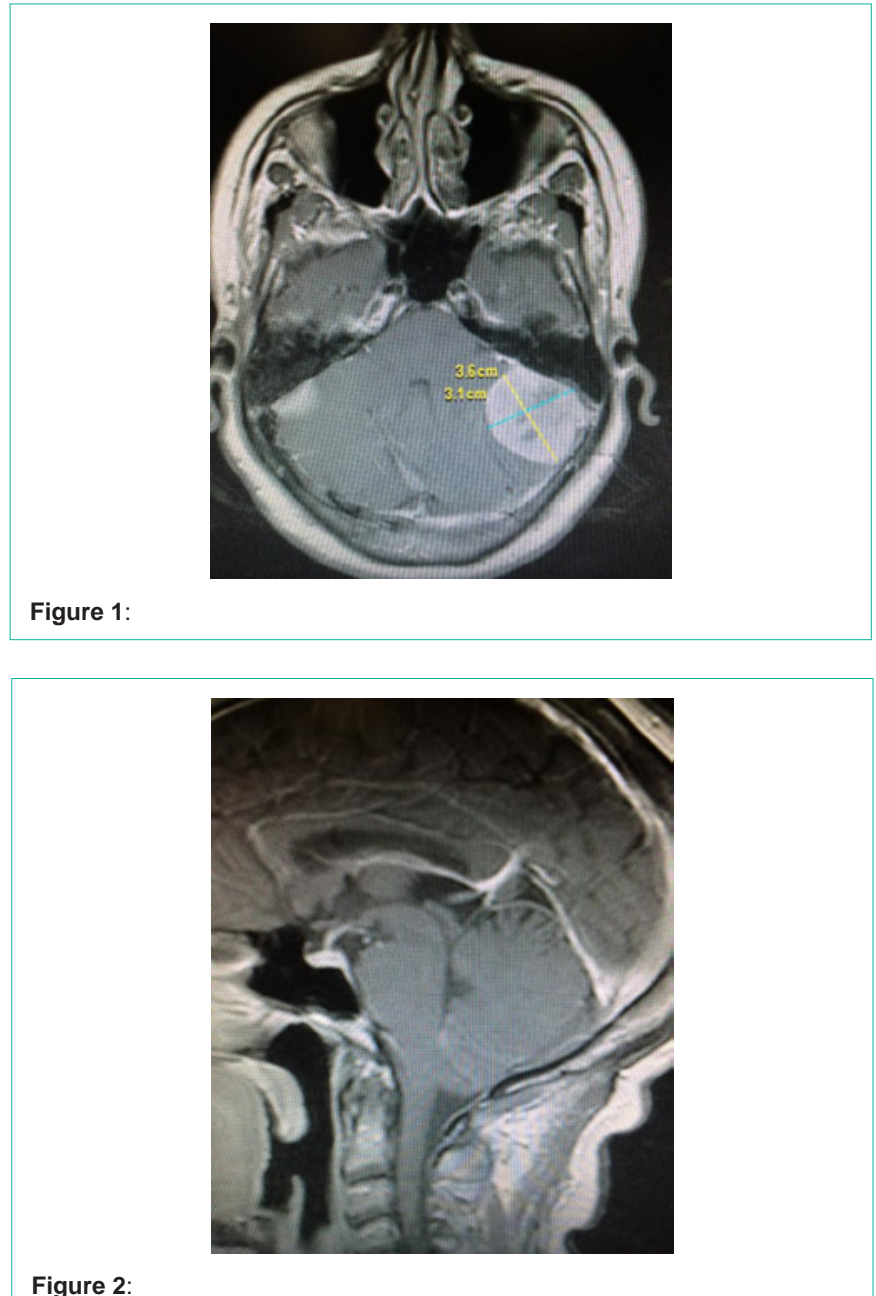

exam was normal.

MRI of the brain with and without gadolinium obtained just prior to her office visit in February 2014 suggested that the two meningiomas had enlarged. The leS-sided mass measured $4.4 \mathrm{x}$
Austin Neurosurg Open Access - Volume 7 Issue 1 - 2021 Submit your Manuscript | www.austinpublishinggroup.com Collado et al. () All rights are reserved
Citation: Shiau JS, Collado JA, Danielle Ruggiero D and Skrypek AR. De Novo Chiari I Malformation and Syringomyelia Arising from Enlarging Posterior Fossae Meningioma: Case Report and Discussion. Austin Neurosurg Open Access. 2021; 7(1): 1067. 

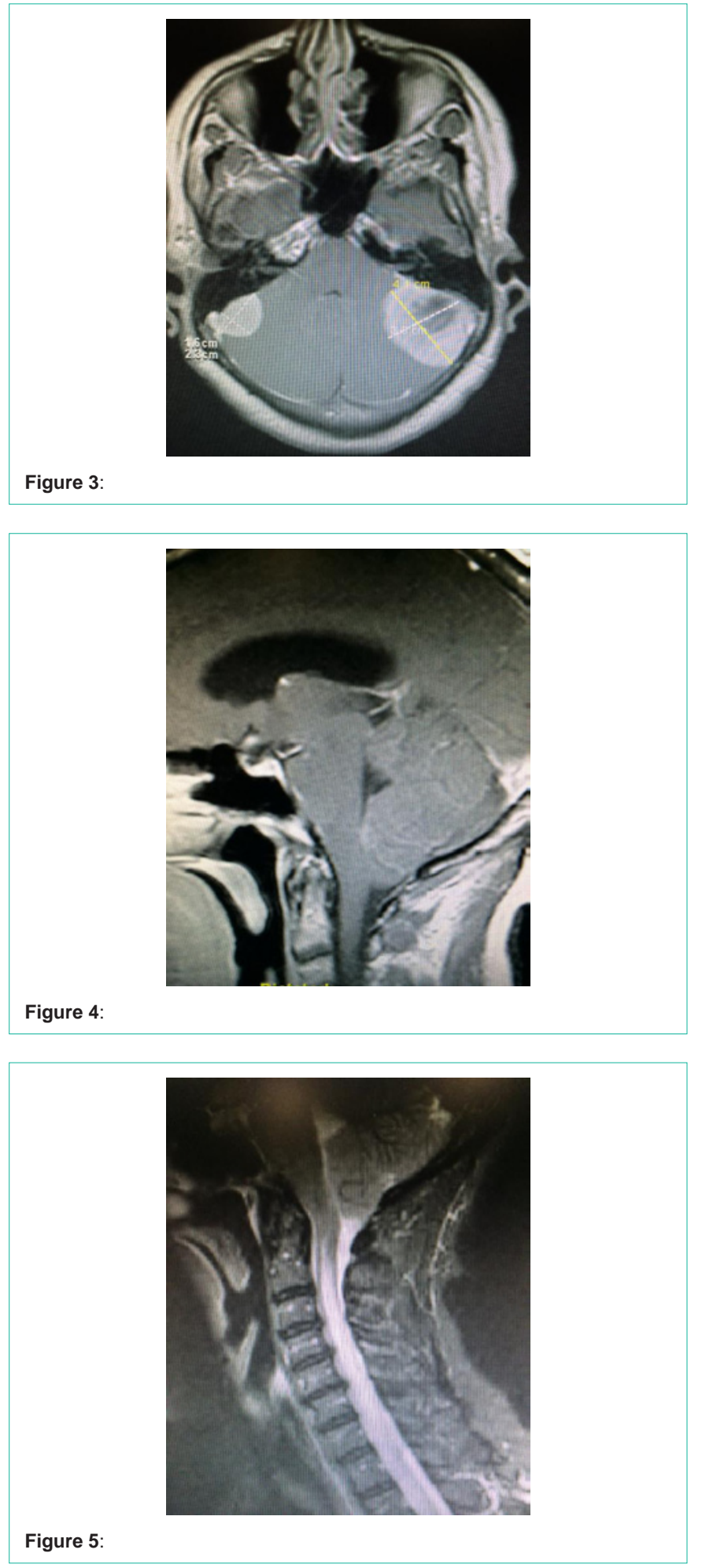

$3 \times 4 \mathrm{~cm}$; the right-sided mass measured $2.3 \times 1.6 \times 2.2 \mathrm{~cm}$. There was interval development of moderate ventricular dilatation with transependymal edema and tonsillar herniation consistent with a new Chiari I malformation (Figure 3 and 4). There was a suggestion of a new cervical syrinx.

A dedicated MRI of the cervical spine with and without
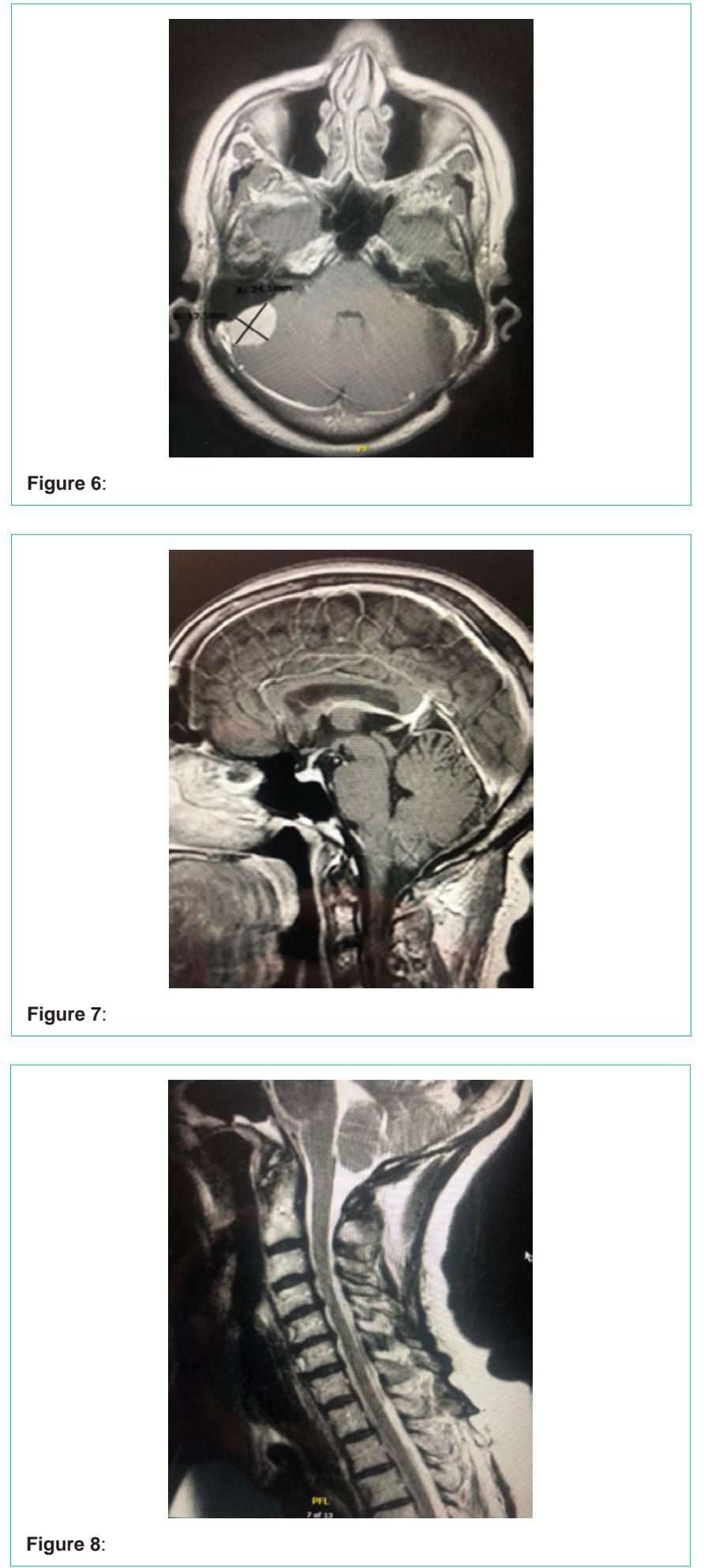

gadolinium was obtained. This study showed mild underlying cervical spondylosis and, most impressively, a non-enhancing syringomyelia extending from C2 down to T3 (Figure 5).

A suboccipital craniectomy for resection of the leS meningioma was recommended and performed on March 19, 2014. She did well, and her preoperative symptoms completely resolved. Postoperative 
MRIs showed complete resection of the leS cerebellar meningioma and subsequent resolution of her Chiari and syrinx (Figure 6-8).

\section{Discussion}

To our knowledge, this is the first case report with documented sequential enlargement of a posterior lesion resulting in Chiari I malformation and syrinx with the resolution of both pathologies post-resection. There are other reports of infratentorial lesions causing both Chiari I and syringomyelia with similar postoperative courses. Posterior fossae tumors associated with syringomyelia or syringobulbia include meningiomas [1-8], Cerebellar astrocytoma [9], brainstem glioma [10], fourth ventricular epidermoid tumor [11], and cerebellar hemangioblastoma [12]. However, patients in these specific reports present with the pathologies; there are no images prior to the appearance of the tonsillar herniation or syrinx.

This report is unique in the radiographic evolution demonstrating the de novo development of Chiari I and syrinx with the corresponding progression of tumor size.

There are multiple theories that attempt to explain the pathophysiology of syringomyelia. Broadly, there are three types of spinal cord cavities/syrinxes showing three types of communication with the fourth ventricle and central canal: communicating and noncommunicating central canal syrinxes, and extracanalicular syrinx [13-15]. An extracanicular syrinx is associated with spinal cord trauma and injury [16]; however, intramedullary spinal tumors with associated syrinx must always be ruled out.

A communicating syrinx or hydromyelia is predominantly found in children with hydrocephalus [15]. Syringomyelia or a noncommunicating central canal syrinx is a cavity consisting of a focal dilation of the central canal, separated from the fourth ventricle by a syrinx-free segment of the spinal cord. This cyst occurs primarily in adult patients with disruption of CSF flow near the cervicomedullary junction. Pathophysiology of a syringomyelia has been historically debated.

Initial theories assumed a communication between the fourth ventricle and the central canal. For instance, Gardner's Theory [17] suggests that the flow of cerebrospinal fluid is disturbed by a congenital imperforation of Magendie's foramen. A water-hammer effect is then produced due to the Cerebrospinal fluid movement (CSF) out of the cisterna magna, leading to augmentation of the central canal from the fourth ventricle, producing a syringomyelia. Williams and Timperley [10] reported three cases of syringomyelia with brainstem gliomas and postulated that an obstruction of the subarachnoid space at the foramen magnum could act as a check valve, allowing CSF to cross above the foramen magnum more readily than below, resulting in a craniospinal pressure dissociation. Activities, such as coughing, exacerbate this pressure gradient resulting in spinal fluid flowing from the fourth ventricle into the central canal [18-21], resulting in syringomyelia.

These hydrodynamic hypotheses are based on the theoretical presumption that there must be a direct flow of CSF from the ventricle to the central canal. Neuropathological investigations $[13,22]$ and radiographic studies [15] show that a communication between the syrinx and the fourth ventricle does not exist in syringomyelia, only in the hydromyelia. One explanation is that syringomyelia fluid arises from the CSF in the spinal subarachnoid space [23]. Ball and Dayan [24] emphasize the importance of activities that increase thoracic or abdominal pressure. The subsequent increase in epidural venous pressure and spinal CSF pressure causes the CSF to seep along Virchow-Robin spaces into the spinal cord to forma a syrinx. Aubin et al. [25] documented the transneuronal movement of cerebrospinal fluid into the spinal cord by comparing the CT density of the spinal cord, subarachnoid space, and syringomyelic cavity.

Foramen magnum tumors can divert the spinal CSF away from the intracranial subarachnoid space and into the spinal cord parenchyma along the Virchow-Robin space [23]. Phase- contrast/ cine MRIs indicate that an irregular flow of cerebrospinal fluid in the subarachnoid space of the spinal cord may force fluid into the central canal through the interstitial space of the spinal cord [14].

A similar phenomenon occurs in Chiari I malformations when cerebellar tonsils obstruct the foramen magnum. Heiss et al., Levy et al., and Oldfield et al. [26-28] suggest that the cardiac cycle creates pressure fluctuations and pulsations that drive spinal subarachnoid CSF into the cord parenchyma. In Chiari I, the amount of CSF crossing the cranial-cervical junction decreases. The tonsils move inferiorly during systole and superiorly during diastole driving the spinal subarachnoid CSF like a piston. The resultant high-amplitude pulsations drive CSF into the cord along perivascular spaces.

Levine [23] proposes an alternative explanation for the formation of syringomyelia associated with a lesion at the foramen magnum. The differentially higher CSF pressure above the block at the foramen magnum results in changes in the transmural venous pressure. Erect posture, coughing or straining, and pulsatile fluctuations of CSF pressure during the cardiac cycle will transiently widen the differential. This results in capillary constriction and vasodilation above and below the block at the foramen magnum respectively, eventually causing partial breakdown of the blood-spinal cord barrier, allowing ultrafiltrate of crystalloids and low protein to accumulate within the spinal cord, forming a syrinx.

Likewise, Koyanagi [29] believes that in the setting of a Chiari I malformation and tonsillar herniation, there is reduced compliance of the posterior spinal veins and the spinal subarachnoid space resulting in diminished absorption of extracellular fluid through the intramedullary venous channels causing formation of syringomyelia [30-35].

Surgical resection of tumor re-establishes CSF flow with resolution of both Chiari I and syrinx [2,6].

\section{Conclusion}

This case report definitively illustrates how an enlarging posterior fossae meningioma can result in a de novo development of a Chiari I malformation and associated syringomyelia. Resection of the tumor resolved the tonsillar herniation and re-established CSF flow resulting in the disappearance of the syrinx. Although generally accepted as true, this case report further supports the pathophysiology of the spinal cord syrinx development as crowding and subsequent disruption of CSF flow at the craniocervical junction.

\section{References}

1. Anegawa S, Hayashi T, Torigoe R, Iwaisako K, Higashioka H. Cerebellopontine 
angle meningioma causing asymptomatic syringomyelia: case report. Neurol Med Chir (Tokyo). 1997; 37: 624-626.

2. Del Maestro M, De Paulis D, Ricci A, Di Cola F, Galzio R. Syringobulbia associated with posterior fossa meningioma: a review of the literature. Childs Nerv Syst. 2014; 30: 1749-1752

3. Fukui K, Kito A, Iguchi I. Asymptomatic syringomyelia associated with cerebellopontine angle meningioma. Case report. Neurol Med Chir (Tokyo) 1993; 33: 833-835.

4. Hirata Y, Matsukado Y, Kaku M. Syringomyelia associated with a foramen magnum meningioma. Surg Neurol. 1985; 23: 291-294.

5. Jaiswal AK, Chandra PS. Cerebellopontine angle meningioma with acquired chiari and syringomyelia: neuroimage. Neurol India. 2001; 49: 323.

6. Kankane VK, Jaiswal G, Gupta TK. Large tentorium meningioma causing chiari malformation type-1 with syringomalia with complete resolution of syrinx and chiari aSer surgical excision: rare case report with review of literature. Romanian Neurosurgery. 2016; 1: 127-131.

7. Kosary IZ, Braham J, Shaked I, Tadmor R. Cervical syringomyelia associated with occipital meningioma. Neurology (Minneap). 1969; 19: 1127-1130.

8. Urasaki E, Soejima T, Yokota A, Matsuoka S. Association of asymptomatic syringomyelia with tentorial meningioma. No Shinkei Geka. 1989; 17: 985989.

9. Kumar C, Panagapoulos K, Kalbag RM, McAllister V. Cerebellar astrocytoma presenting as a syringomyelic syndrome. Surg Neurol. 1987; 27: 187-190.

10. Williams B, Timperley WR. Three cases of communicating syringomyelia secondary to midbrain gliomas. J Neurol Neurosurg Psychiatry. 1977; 40: 80-88.

11. Kan S, Fox AJ, Vinuela F, Barnett HJM, Peerless SJ. Delayed CT metrizamide enhancement of syringomyelia secondary to tumor. AJNR. 1983; 4: 73-78.

12. De Reuck J, Alva J, Roels H, Vander Eecken H. Relation between syringomyelia and von Hippel- Lindau's disease. Eur Neurol. 1974; 12: 116127

13. Hinokuma K, Ohama E, Oyanagi K, Kakita A, Kawai K, Ikuta F. Syringomyelia: a neuropathological study of 18 autopsy cases. Acta Pathol Jpn. 1992; 42 25-34.

14. Ho-man J Zur Lehre der Syrimgomyelie. Dtsch Z Nervenheilkd. 1893; 3 1-136.

15. Milhorat TH, Kotzen RM, Anzil AP. Stenosis of central canal of spinal cord in man: Incidence and pathological findings in 232 autopsy cases. J Neurosurg 1994; 80: 716-722.

16. Vannemreddy SS, Rowed DW, Bharatwal N. Posttraumatic syringomyelia: predisposing factors. Br J Neurosurg. 2002; 16: 276-283

17. Fox B, Muzumdar D, De Monte F. Resolution of tonsillar herniation and cervical syringomyelia following resection of a large petrous meningioma: case report and review of literature. Skull Base. 2005; 15: 89-98.

18. Williams B. The distending force in the production of "communicating syringomyelia". Lancet. 1969: 2: 189-193.
19. Williams B. Current concepts of syringomyelia. Br J Hosp Med. 1970; 4: 331 342.

20. Williams B. On the pathogenesis of the Chiari malformation. Z Kinderchir Grenzgeb. 1977; 22: 533-553.

21. Williams B. Simultaneous cerebral and spinal fluid pressure recordings: 2. Cerebrospinal dissociation with lesions at the foramen magnum. Acta Neurochir. 1981; 59: 123-142.

22. Milhorat TH, Capocelli AL Jr, Anzil AP, Kotzen RM, Milhorat RH. Pathological basis of spinal cord cavitation in syringomyelia: analysis of 105 autopsy cases. J Neurosurg. 1995; 82: 802-812.

23. Levine DN. The pathogenesis of syringomyelia associated with lesions at the foramen magnum: a critical review of existing theories and proposal of a new hypothesis. J Neurol Sci. 2004; 220: 3-21.

24. Ball MJ, Dayan AD. Pathogenesis of syringomyelia. Lancet. 1972; 2: 799801.

25. Aubin ML, Vignad J, Jardin C, Bar D. Computed tomography in 75 clinical cases of syringomyelia. AJNR. 1981; 2: 199-204.

26. Heiss JD, Patronas N, DeVroom HL, Shawker T, Ennis R, Kammerer W, et al. Elucidating the pathophysiology of syringomyelia. J Neurosurg. 1999; 91 553-562

27. Levy El, Heiss, JD, Kent MS, Riedel CJ, Oldfield EH. Spinal cord swelling preceding syrinx development. J Neurosurg. 2000; 92: 93-97.

28. Oldfield EH, Muraszko K, Shawker TH, Patronas NJ. Pathophysiology of syringomyelia associated with Chiari I malformation of the cerebellar tonsils. Implications for diagnosis and treatment. J Neurosurg. 1994; 80: 3-15.

29. Koyanagi I, Houkin K. Pathogenesis of syringomyelia associated with Chiari type 1 malformation: review of evidences and proposal of a new hypothesis. Neurosurg Rev. 2010; 33: 271-284.

30. Bhatoe HS. Tonsillar herniation and syringomyelia secondary to a posterior fossa tumor. Br J Neurosurg. 2004; 18: 70-71.

31. Bouras TI, Kouyialis T, Boviatsis EJ, Sakas DE. Symptomatic syringomyelia secondary to clinically obscure infratentorial tumour. Br J Neurosurg. 2006; 20: 48-50.

32. Gardner WJ. Hydrodynamic mechanism of syringomyelia: Its relationship to myelocele. J Neurol Neurosurg Psychiat. 1965; 28: 247-259.

33. Karttunen A, Heikkinen E, Tuominen J, Jartti P. Secondary syringomyelia disappearing aSer removal of tentorial meningioma. Acta Neurochir (Wien). 2002; 144: 741-742.

34. Klekamp J, Samii M, Tatagiba M, Sepehrnia A. Syringomyelia in association with tumors of the posterior fossa. Pathophysiological considerations, based on observation on three related cases. Acta Neurochir (Wien). 1995; 137: 38-43.

35. Tachibana S, Harada K, Abe T, Yamada H, Yokata A. Syringomyelia secondary to tonsillar herniation caused by posterior fossa tumors. Surg Neurol. 1995; 43: 470-477. 